\title{
Clinical Grading of Intrahepatic Cholestasis Pregnancy
}

\author{
Meena Pradhan, ${ }^{1}$ Yong Shao' \\ 'Department of Obstetrics and Gynecology, the first affiliated hospital of Chongqing medical university, Chongqing, China.
}

\begin{abstract}
Intrahepatic cholestasis of pregnancy (ICP) is the pregnancy induced liver disorder causing intense itching of palm, sole or even whole body especially in the evening at late second and third trimester. This disease is categorized into mild and severe ICP according to raised level of LFT including serum level of bile acid and cholic acid. ICP has less morbidity to mother but significant risk to fetus in uterus. The predisposing element to cause intense pruritus is because of high amount of bile acid in maternal serum. Toxic bile acids affect fetal cardiomyocytes retained in fetus body causing sudden intrauterine fetal death. ICP is commonly found in winter months and mostly itching of body occurs in the evening after sunset. Fetus in uterus is unsafe if mother's bile acid exceeds normal value. ICP is successfully treated with Ursodeoxycholic acid (UDCA), S-adenosyl methionine (SAME), Dexamethasone and vitamin K.
\end{abstract}

Keywords: itching; bile acid; obstetric cholestasis; Ursodeoxycholic cholic acid.

\section{INTRODUCTION}

Intrahepatic cholestasis of pregnancy (ICP) is a disease develops during second half to third trimester of pregnancy and identified by pruritus, fasting biochemical disturbances in liver function tests (LFTs) and raised maternal serum bile acid, the most powerful predictor for cholestasis.

Kremer et al found that the main element stimulating itch sensation was Lysophosphatidic acid (LPA). In animal model, increased serum level of enzyme autotaxin is involved in converting Lysophosphatidylcholine into LPA. ${ }^{1}$ ICP has negative effect on fetal outcome with increased risk of spontaneous preterm delivery $14 \%$, meconium stained amniotic fluid at delivery $44 \%$, fetal distress $22 \%$ and still birth. ${ }^{2,3}$ The incidence of ICP varies throughout the world; China 5.2\%, ${ }^{4}$ Scandinavians $2 \%$. In South America, Chile had high rate (14\%) of ICP in last seventies had declined to $6 \% .{ }^{5}$ ICP considerably involves in perinatal mortality and morbidity attribute to preterm delivery in multiple gestations are more vulnerable. ${ }^{6}$ The tendency to inheritance in mother's family is $16 \%$ and high recurrence rate. $^{7}$

\section{ETIOLOGY AND PATHOGENESIS}

Exact pathogenesis of ICP is still unknown to obstetrician. However, several factors involved in pathogenesis of ICP are high amount of estrogen and progesterone hormone production at third trimester, genetic mutation and environment especially in winter months. ICP is the result of insufficient liver capacity to metabolize high amounts of placenta-derived sex steroids during pregnancy. ${ }^{8}$ Dann et al. ${ }^{9}$ reported random blood lipid profile test for early detection of ICP had abnormal lipid profiles and significant increased concentration of low density lipoprotein (LDL) and decrease level of high density lipoprotein (HDL) before development of ICP. Administration of an estrogen in experimental animal models developed cholestasis featuring impaired function of specific transporter proteins such as the $\mathrm{Na}+$ /taurocholate co-transporting polypeptide [NTCP],

Correspondence: Dr. Yong Shao, Department of Obstetrics and Gynecology, The First Affiliated Hospital of Chongqing Medical University Chongqing 400016, P. R. China. Email: cqshaoyong@163.com, Phone: 08613101280793. 
the bile salt export pump (BSEP, gene ABCB11) and the multidrug resistance associated protein-2 (MRP2, gene ABCC2). ${ }^{10}$ These specific proteins transporter inhibited at the transcriptional level that slows flow of bile and excretory function from liver. ${ }^{11}$ In the genetic study, rats liver autopsy revealed increased impaired activation of cholesterol 7 alpha hydroxylase (CYP7A1), cholesterol 27 alpha hydroxylase (CYP27A1), cholesterol 8 alpha hydroxylase (CYP8B1) genes that are responsible for converting cholesterol to bile acid. ${ }^{12}$ High level of estrogen deactivated mRNA expression of peroxisome proliferators-activator receptor alpha (PPAR $\alpha$ ). It increased the abnormal expression of CYP7B1 by stimulating the estrogen receptor (ER) and deactivation of (PPAR $\alpha$ ). ${ }^{13,14}$ High level of estrogen cause functional disorder of immune system leading to decreased CD8 counts in ICP. ${ }^{15}$ High amount of monosulfated or disulfated progesterone metabolites (3- and 5-isomers) stimulated transinhibition of the canalicular bile salt transporter BSEP resulting retention of bile acid in maternal serum. It suggested malfunction of biliary canalicular transporters normally responsible for bile secretion from hepatocytes into bile duct. ${ }^{16}$ Intrahepatic cholestasis of pregnancy showed genetic mutations in the hepatic phospholipids transporter adenosine triphosphate binding cassette, subfamily $B$ member 4 (ABCB4), aminophospholipid transporter adenosine triphosphate (ATP8B1) and BSEP. ${ }^{17-19}$ However, Savender et al reported no major role of ATP8B1 genetic mutation from ICP families. ${ }^{7}$ Favre et al. ${ }^{20}$ reported a case with genetic alternation occurred in BSEP had higher serum aminotransferase level (ALT) but low bile acid level leading to unexpected intrauterine fetal death. Higher incidence of ICP was found in mothers of patients with multidrug resistance p-glycoprotein- 3 (MDR3), progressive familial Intrahepatic cholestasis type-3 (PFIC3) and benign recurrent Intrahepatic cholestasis type-1 (BRIC1) are genetically associated with disorders of bile secretion responsible for cholestasis. PFIC2 also caused gene mutation in BSEP main agent responsible for the ATP-dependent secretion of bile acids across the canalicular membrane. ${ }^{21}$ Kawamata et al, ${ }^{22}$ reported activation of bile acid specific G-proteincoupled receptor (TGR5) suppressed phagocytic activity of macrophage functions. Activation of TGR5 in bile acids of lithocholic acid (LCA), deoxycholic acid (DCA) and chenodeoxycholic acid (CDCA) stimulate lipopolysaccharide (LPS) resulting potential toxicity to liver. ${ }^{23}$ TGR5 induced nitric oxide production by cyclic AMP-dependent activation of endothelial nitric oxide synthase caused endotoxemia as a result of increased serum bile acid level. ${ }^{24}$ Moreover, Selenium acts as a cofactor of several enzymes in the oxidative metabolism of liver. In Chilli and Finland decreased level of selenium was identified in maternal serum of ICP population. Since the consumption of selenium containing food begun in 1991 in this country, there has been a decrease in ICP incidence. ${ }^{25}$ ICP is more commonly occurring in the winter months and itching increases usually in the evening.

\section{FETAL PATHOPHYSIOLOGY}

Mother's clinical presentation resolves soon after delivery and LFTs normalize within one to two weeks. Sudden fetal death in term pregnancy is the most unknown cause of ICP so far. In order to minimize its adverse complication and sudden fetus loss in uterus, review of literature to update current management protocol is mandatory. Elevated levels of maternal serum bile acids intoxicates intra-uterine fetal environment. Fetal chamber contain higher amount of bile acid than maternal serum. In amniotic fluid, umbilical cord and meconium bile acid content is higher because of reduced function of excretory function from placenta. ${ }^{26}$ In fetus of ICP, the cardiac autonomic imbalance is associated with increased sympathetic activity leading to prolonged PR interval and fetal arrhythmia. ${ }^{27}$ In animal model, Shao et al revealed high serum bile acid impaired fetal cardiomyocytes causing arrhythmia and sudden intrauterine death. ${ }^{28}$ In rat cardiac myocytes, exposure to the bile acid taurocholate (TCA) affected cardiac contractility directly and abnormal calcium destabilization from partial agonist of the M2 receptor. ${ }^{29}$ Increased level of maternal serum bile acid developed fetal arrhythmia and desynchronization of cell coupling during increasing gestational period. ${ }^{30}$ Another study reported that increased serum bile acid induced human chorionic vein constriction, and abrupt reduction in placental transfer of oxygenated blood flow to the fetus. ${ }^{31}$ This may result in decreased fetal elimination of toxic bile salts that may attribute to fetal distress, higher risk of premature labour and still birth. ${ }^{32}$ High levels of maternal TBA effect placental transport of bile acid and placental hormone production. ${ }^{33}$ In 2005, Shao et $\mathrm{al}^{34}$ reported pathophysiological changes in the liver and placenta of the ICP rats. Dilated bile canalicular and deposition of granules and vacuole like substances found in the syncytotrophoblast of the ICP rats.

Recent study reported cholestasis of pregnancy affect fetal pulmonary tissues, congestion of the interstitial lung capillaries, enlargement of alveolar septum and focal hemorrhage. Moreover, hyperbileacedemia changed morphology of pueumonocytes type II with decreased microvilli, mitochondrion vacuolization and cytoplasm disintegration and loss of laminar body of ICP fetal rats. ${ }^{35}$ Despite of lung maturity in the amniotic fluid, fetal born to severe ICP developed bile acid induced pneumonia. ${ }^{36}$ Author hypothesized that by opposite action of phospholipase A2, breakdown of phopsphatidylchoines to lysophosphatidylcholines 
caused lack of surfactant activity a principal cause for development of severe respiratory distress syndrome (RDS) in newborn. ${ }^{37}$ RDS occurred in $66.7 \%$ neonates born from ICP pregnant mother. ${ }^{38}$

\section{CLINICAL FEATURES}

ICP is presented with typical feature of pruritus starting in second half of pregnancy and disappearing soon after delivery. It often affects palms, soles of the feet and is worse at night. Mild jaundice with moderately elevated serum levels of conjugated bilirubin occurred in $10-15 \%$ cases of ICP. Jaundice typically developed 1-4 weeks after the onset of pruritus. The disruption of normal bile salt function can impair fat malabsorption and vitamin $\mathrm{K}$ absorption resulting steatorrhea and prolonged prothrombin time may risk for postpartum hemorrhage. ${ }^{39}$ ICP also associates with gallbladder stone, ${ }^{40}$ and post cholecystectomy. Ultrasonography confirms diagnosis.

\section{DIAGNOSIS}

In 2004, Glantz et al categorized ICP into two type; mild ICP and severe ICP. In mild ICP group TBA referenced up to $40 \mu \mathrm{mol} / \mathrm{dl}$; severe ICP above $40 \mu \mathrm{mol} /$ $\mathrm{dl}{ }^{41}$ this reference value significantly reduced adverse fetal outcome. However, case reports with bile acid concentration below $40 \mu \mathrm{mol} / \mathrm{l}$ had fetal death occurred with prolonged deceleration in CTG. ${ }^{42}$

In the same year 2004, our hospital followed standard protocol for treating ICP categorizing into mild and severe degree according to elevated serum liver function test, bile acid and additional marker cholylglycine (CG) or cholic acid level. The standard reference value established for mild ICP (MICP) are TBA $<40 \mu \mathrm{mol} / \mathrm{L}$ (normal $<20 \mu \mathrm{mol} / \mathrm{L}$ ), TBIL $<21 \mu \mathrm{mol} / \mathrm{L}$ (normal $<20$ $\mu \mathrm{mol} / \mathrm{L}), \quad \mathrm{DBIL}<6 \mu \mathrm{mol} / \mathrm{L}$ (normal $<6), \quad \mathrm{ALT}<250$ $\mathrm{U} / \mathrm{L}$ (normal $<40 \mathrm{U} / \mathrm{L}$ ), AST $<250 \mathrm{U} / \mathrm{L}$ (normal $<40$ $\mathrm{U} / \mathrm{L}$ ), $\mathrm{CG}<30 \mathrm{mg} / \mathrm{L}$ (normal $<3 \mathrm{mg} / \mathrm{L}$ ). MICP indicates no increased risk, but does not mean that the fetus is unaffected. For severe ICP (SICP) reference values are TBA $>40 \mu \mathrm{mol} / \mathrm{L}, \mathrm{TBIL} \geq 21 \mu \mathrm{mol} / \mathrm{L}, \quad \mathrm{DBIL} \geq 6$ $\mu \mathrm{mol} / \mathrm{L}, \mathrm{ALT} \geq 250 \mu \mathrm{mol} / \mathrm{L}, \mathrm{AST} \geq 250 \mu \mathrm{mol} / \mathrm{L}, \mathrm{CG} \geq 30$ $\mathrm{mg} / \mathrm{L}$. Clinical symptoms are: 1) severe pruritus, and/ or accompany with other symptom, such as jaundice; 2) early onset ( $<34$ weeks of gestation) of ICP; 3) complicated with multiple pregnancy, or pregnancyinduced hypertension syndrome, or repeated ICP, or previous perinatal mortality resulted from ICP. This standard treatment protocol resulted significant decrease in perinatal morbidity and mortality $(0.7 \% \sim 1.2 \%) .{ }^{43}$ Because of high incidence of spontaneous pregnancy loss in SICP, delivery by 37 weeks of gestation is considered crucial to fetal outcome, though it does not completely eliminate risk associated with the condition. Serum cholic acid level is another sensitive marker that significantly increases in ICP. The ratio of cholic/ chenodeoxycholic (CG/CDCA) acid level increases whereas the ratio of glycine- to taurine conjugated bile acids decreases. ${ }^{44}$ According to biochemical marker clinical grading of ICP is mandatory for treatment or prevention of sudden fetal demise near term.

In the study of bile acid profiles, the concentrations of taurocholic acid (TCA), glycocholic acid (GCA), tauroursodeoxycholic acid (TUDCA), glycocholic deoxycholic acid (GCDCA) and total bile acids were significantly higher in serum of women with ICP. ${ }^{45}$ Further, Tribe et al, ${ }^{46}$ found bile acid profile in serum concentrations of TCA, GCA, taurolithocholic acid (TLCA), taurochenodeoxy cholic acid (TCDCA), GCDCA were significantly elevated but Lithocholic acid LCA significantly decreased in ICP compared to control group. However, author reported LCA marker found to be raised in ICP. ${ }^{47}$ Importantly, $\mathrm{Yu} \mathrm{J}$ et al. reported increased serum LCA cut down expression of BSEP resulting in increased bile acid retention in liver leading to cholestasis and hepatic damage. ${ }^{45}$

The phenomenon of Asymptomatic Hypercholanemia of pregnancy (AHP) has recently been reported. AHP is defined as raised serum bile acids in pregnancy in the absence of clinical symptoms and other biochemical markers. ${ }^{48}$ AHP was reported to affect approximately $10 \%$ of the pregnant population and $2-3 \%$ of women with AHP in the second trimester subsequently developed ICP. ${ }^{49}$ Maternal hypercholanemia can challenge transplacental elimination of fetal bile acid by impairing the placental ability to carry out vectorial BA transfer. ${ }^{50}$

\section{DIFFERENTIAL DIAGNOSIS}

Pruritus is the main clinical feature of ICP. The other types of liver related pregnancy disorder are early HELLP syndrome, acute fatty liver of pregnancy or preeclampsia. The differential diagnosis of pruritus gravida without icterus should be focused on possible cause of parasitic infection, skin diseases (eczema, scabies, and urticarial papules), allergic infection, diabetes and other metabolic disease. In patients with high ALT or bilirubin, acute viral hepatitis, choledocholithiasis and toxic hepatitis, hyperbilirubinemic state are to be excluded. Bile duct obstruction causes an increase in GGT and ALP. Therefore abdominal sonography confirms the diagnosis.

\section{MANAGEMENT}

According to degree of severity, active management 
should be done to relief pruritus and provide adequate obstetric management in order to prevent fetal distress or sudden fetal death. It has been reported that protocols including weekly fetal cardiotochograph (CTG) monitoring is highly effective for detecting non-reassuring fetal heart rate of intrapartum fetal asphyxia. Intrapartum CTG can detect abnormalities of fetal heart rate variability; tachycardia or bradycardia. ${ }^{51}$ More recently, a case described fetal atrial flutter tachyarrhythmia (220-230 bpm) during labour at 37 weeks of gestation. ${ }^{52}$ After delivery neonate can continuously develop tachyarrhythmia for more than a month and neonate can die from AV block. ${ }^{53}$ Child born from severe ICP should closely observe cardiac function as well. ${ }^{54}$ In most patients, maternal bed rest, mild sedation and a low fat diet may relief pruritus but fetal risk does not seem to be modified by this strategy.

Many pharmacological agents have been used in the treatment of intrahepatic cholestasis of pregnancy. These includes Phenobarbital (100 mg qd), hydroxyzine (25-50mg qd), glutathione precursor S-adenosyl methionine (SAME) (800 mg qd or $1600 \mathrm{mg}$ qd orally), cholestyramine (8-16 g/d), and dexamethasone $(12 \mathrm{mg}$ qid for seven days followed by tapering dose). These agents showed less clinical benefit with significant side effects. Vitamin $\mathrm{K}$ deficiency and coagulopathy observed with the use of cholestyramine in high doses. ${ }^{55}$ Oral phytomenadione (vitamin K) should be given from $32^{\text {nd }}$ week of gestation in ICP to reduce the risk of maternal coagulopathy, ${ }^{56}$ as well as to new born child to prevent intracranial hemorrhage.

The hydrophilic bile acid Ursodeoxycholic acid (UDCA) is a promising drug given orally in dose of $15 \mathrm{mg} / \mathrm{kg}$ bodyweight per day for two or three weeks. It definitely improves maternal pruritus condition, serum bilirubin, aminotransferase, TBA, and cholic acid. ${ }^{57}$ It activates transporter protein into the canalicular membrane and improves bile salt export from the liver. It restores impairment of maternal-placental bile acid transport across the placental trophoblasts. ${ }^{6}$ It also protects cardiomyocytes from bile acid induced arrhythmias in vitro model. ${ }^{58}$ After UDCA treatment serum concentrations of individual bile acids CA, TCA, TCDA, and TDCA significantly reduced but LCA increased along with serum concentration of UDCA. ${ }^{46}$ It improved defective genetic mutation in heterozygous $A B C B 11$ bile acid transporter maintaining normal liver function and decreased pruritus. ${ }^{59}$

Recently, combined therapy with UDCA and Polyunsaturated phosphatidylcholine (PPC) has accelerated improvement of intense itching and corrected abnormal liver function test. ${ }^{60} \mathrm{PPC}$ is effective treatment for preventing liver damage, ductular proliferation and fibrosis caused by biliary cholestasis. ${ }^{61}$ PPC is also regarded as an important transcriptional activating factor that directly acts on gene expression of mRNA PPAR $\alpha$ in bile acid as well as other cholesterol metabolism with induction of hepatic fatty acid oxidation. ${ }^{62}$ Rocaglia $\mathrm{N}$ et $\mathrm{al}^{6}{ }^{63}$ recommend active management with elective delivery usually before or at 37 weeks of gestation for sever ICP. Delivery is indicated when fetal lung maturity is achieved even at 35-36 weeks of gestation in severe cases and at 37-38 weeks of gestation in mild cases to prevent stillbirth in late pregnancy. ${ }^{64}$ However, recently published data suggest that with active management, ICP can be safely carried out up to 38 weeks under close monitoring. ${ }^{65}$ Even after birth, neonate must be given high priority because of possible development of unexpected RSD diagnosed from severe ICP mother.

\section{SUMMARY}

In Mild ICP (MICP) women can be treated in outpatient department with weekly CTG, Ultrasound for fetal movement and S/D umbilical artery marker for hypoxia, dexamethasone and hepatoprotective medicine. According to maternal pelvis condition, normal delivery is safe both for mother and fetus. For Severe ICP (SICP) mother is advised for admission, prophylaxis intramuscular dexamethasone, SAME or UDCA etc treatment. If before 35 weeks of gestation there is fetal distress, estimating fetus is alive can also terminate by caesarean section after fetal lung maturity. Despite the complex pathogenesis involved in genetic mutation, hormonal and environmental component during pregnancy adverse effect to fetus can be reduced. In addition, detailed study of the consequences of maternal cholestasis on both placental transport function and fetal hepatic transport capacity may help to prevent fetal distress and IUD in the clinical setting of ICP. UDCA along with PPC are beneficial for symptomatic relief of pruritus and decrease in abnormal liver function test, bile acid and cholic acid level.

\section{ACKNOWLEDGEMENT}

We would like to thank to Dr. Rabindra M Bajracharya, Ms. Aishworya Bajracharya, Mr. Sher Bahadur Pradhan and Mrs. Shanti Pradhan for kind support and guidance. 
1. Kremer AE, Martens JJ, Kulik W, Ruëff F, Kuiper EM, van Buuren HR et al. Lysophosphatidic acid is a potential mediator of cholestatic pruritus. Gastroenterology. 2010 Sep;139(3):1008-18.

2. Alsulyman OM, Ouzounian JG, Ames-Castro M, Goodwin TM. Intrahepatic cholestasis of pregnancy: perinatal outcome associated with expectant management. Am J Obstet Gynecol. 1996;175:957-60.

3. Turunen K, Sumanen M, Haukilahti RL, Kirkinen P, Mattila K. Good pregnancy outcome despite intrahepatic cholestasis. Scand J Prim Health Care. 2010;28:102-7.

4. Wang XD, Yao Q, Peng B, Zhang L, Ai Y, Ying AY et al. A clinical analysis of intrahepatic cholestasis of pregnancy in 1241 cases. Zhonghua Gan Zang Bing Za Zhi. 2007 Apr;15(4):291-3.

5. Kondrackiene J, Kupcinskas L. Intrahepatic cholestasis of pregnancy-current achievement and unsolved problems. World J Gastroenterol. 2008;14:5781-8.

6. Gonzalez MC, Reyes H, Arrese M, Figueroa D, Lorca B, Andersen $\mathrm{M}$ et al. Intrahepatic cholestasis of pregnancy in twin pregnancies. J Hepatol. 1989;9:84-90.

7. Savander M, Ropponen A, Avela K, Weerasekera N, Cormand B, Hirvioja ML et al. Genetic evidence of heterogeneity in intrahepatic cholestasis of pregnancy. Gut. 2003 Jul;52(7):1025-9.

8. Davidson KM. Intrahepatic cholestasis of pregnancy. Semin Perinatol. 1998;22:104-11.

9. Dann AT, Kenyon AP, Wierzbicki AS, Seed PT, Shennan AH, Tribe RM. Plasma lipid profiles of women with intrahepatic cholestasis of pregnancy. Obstet Gynecol. 2006;107:106-14.

10. Arrese M, Trauner M, Ananthanarayanan M, Pizarro M, Solís N, Accatino L et al. Down-regulation of the $\mathrm{Na}+$ / taurocholate cotransporting polypeptide during pregnancy in the rat. J Hepatol. 2003 Feb;38(2):148-55.

11. Geier A, Dietrich CG, Gerloff T, Haendly J, Kullak-Ublick GA, Stieger B et al. Regulation of basolateral organic anion transporters in ethinylestradiol-induced cholestasis in the rat. Biochim Biophys Acta. 2003 Jan 10;1609(1):87-94.

12. Wagnert $M$, Trauner $M$. Transcriptional regulation of hepatobiliary transport systems in health and disease: implications for a rationale approach to the treatment of intrahepatic cholestasis. Ann Hepatol. 2005;4:77-99.

13. Shi QY, Lin YG, Zhou Z, Lin YQ, Yan S. Expression of FXR mRNA, PPAR alpha mRNA and bile acid metabolism related genes in Intrahepatic cholestasis of pregnant rats. Zhonghua Gan Zang Bing Za Zhi. 2010 Dec;18(12):927-30.

14. Leuenberger N, Pradervand S, Wahli W. Sumoylated PPARa mediates sex-specific gene repression and protects the liver from estrogen induced toxicity in mice. J Clin Invest. 2009;119:3138-48.
15. Shi $Q$, Liu $S$, Xiong $Q$. The changes of serum estrogen, progesterone and the function of immune system in intrahepatic cholestasis of pregnancy. Zhonghua Fu Chan Ke Za Zhi. 1998;33:724-6.

16. Vallejo M, Briz O, Serrano MA, Monte MJ, Marin JJ. Potential role of trans-inhibition of the bile salt export pump by progesterone metabolites in the etiopathogenesis of intrahepatic cholestasis of pregnancy. J Hepatol. 2006;44:1150-7.

17. Pauli-Magnus C, Lang T, Meier $Y$, Zodan-Marin T, Jung D, Breymann C. Sequence analysis of bile salt export pump (ABCB11) and multidrug resistance p-glycoprotein 3 (ABCB4, MDR3) in patients with intrahepatic cholestasis of pregnancy. Pharmacogenetics. 2004 Feb;14(2):91-102.

18. R Müllenbach, K J Linton, S Wiltshire, N Weerasekera, J Chambers, E Elias et al. ABCB4 gene sequence variation in women with intrahepatic cholestasis of pregnancy. J Med Genet 2003;40:e70.

19. Mullenbach R, Bennett A, Tetlow N, Patel N, Hamilton $\mathrm{G}$, Cheng F et al. ATP8B1 mutations in British cases with intrahepatic cholestasis of pregnancy. Gut. 2005;54:829-34.

20. Favre N, Abergel A, Blanc P, Sapin V, Roszyk L, Gallot D. Unusual presentation of severe Intrahepatic cholestasis of pregnancy leading ot fetal death. Obstet Gynecol. 2009;114:491-3.

21. Sandra S. Strautnieks SS, Bull LN, Knisely AS, Kocoshis SA, Dahl N, Arnell H et al. A gene encoding a liver-specific ABC transporter is mutated in progressive familial intrahepatic cholestasis. Nat Genet. 1998;20(3):233-8.

22. Kawamata Y, Fujii R, Hosoya M, Harada M, Yoshida H, Miwa $\mathrm{M}$ et al. A $\mathrm{G}$ protein-coupled receptor responsive to bile acids. J Biol Chem. 2003 Mar 14;278(11):9435-40.

23. Maruyama T, Miyamoto Y, Nakamura T, Tamai Y, Okada H, Sugiyama $\mathrm{E}$ et al. Identification of membrane-type receptor for bile acids (M-BAR). Biochem Biophys Res Commun. 2002 Nov 15;298(5):714-9.

24. Keitel V, Reinehr R, Gatsios P, Rupprecht C, Gorg B, Selbach $\mathrm{O}$ et al. The G-protein coupled bile salt receptor TGR5 is expressed in liver sinusoidal endothelial cells. Hepatology. 2007;45:695-704.

25. Reyes H, Báez ME, González MC, Hernández I, Palma J, Ribalta J et al. Selenium, zinc and copper plasma levels in intrahepatic cholestasis of pregnancy, in normal pregnancies and in healthy individuals, in Chile. J Hepatol. 2000 Apr;32(4):542-9.

26. Brites D. Intrahepatic cholestasis of pregnancy: change in maternal-fetal bile acid and improvement by Ursodeoxycholic acid. Ann Hepatol. 2002;1:20-8.

27. Strehlow SL, Pathak B, Goodwin TM, Perez BM, Ebrahimi $\mathrm{M}$, Lee RH. The mechanical PR interval in fetuses of women with intrahepatic cholestasis of pregnancy. Am J Obstet Gynecol. 2010;203(5):455. 
28. Shao Y, Yao Z, Lu J, Li H, Wu W, Ding M. Change of heart rate power spectrum and its association with sudden death in the fetuses of rats with intrahepatic cholestasis of pregnancy. Sheng Wu Yi Xue Gong Cheng Xue Za Zhi. 2007 Dec;24(6):1215-9.

29. Gorelik J, Harding SE, Shevchuk AI, Koralage D, Lab M, de Swiet $\mathrm{M}$ et al. Taurocholate induces changes in rat cardiomyocyte contraction and calcium dynamics.Clin Sci (Lond). 2002 Aug;103(2):191-200.

30. Abdul Kadir SH, Ali NN, Mioulane M Brito-Martins M, Abu-Hayyeh S, Foldes G, et al. Embryonic stem cell-derived cardiomyocytes as a model to study fetal arrhythmia related to maternal disease. J Cell Mol Med. 2009;13:3730-41.

31. Sepulveda WH, Gonzales C, Cruz MA, Rudolph MI. Vasoconstrictive effect of bile acids on isolated human placental chorionic veins. Eur J Obstet Gynecol Reprod Biol. 1991;42:211-5

32. Marin JJ, Macias RI, Serrano MA. The hepatobiliary-like excretory function of the placenta. Placetna. 2003;24:431-8.

33. Macias RI, Pascual MJ, Bravo A, Alcalde MP, Larena MG, St-Pierre MV et al. Effect of maternal cholestasis on bile acid transfer across the rat placenta-maternal liver tandem. Hepatology. 2000;31:975-83.

34. Shao Y, Wei Yao Z, Xia Li H et al. Toxic effect of pregnancy Intrahepatic cholestasis on liver and placenta in pregnant rats. World Chin J Digestol. 2005;13:1404-7.

35. Shi Y, Qi HB. Effects of Intrahepatic cholestasis on morphology of fetal lungs in pregnant rat. Zhonghua $\mathrm{Fu}$ Chan Ke Za Zhi. 2010;45:283-6.

36. Williamson C, Gorelik J, Eaton BM, Lab M, de Swiet M, Korchev Y. The bile acid taurocholate impairs rat cardiomyocyte function: a proposed mechanism for intra-uterine fetal death in obstetric cholestasis Clin Sci (Lond). 2001;100:363-9.

37. Zecca E, Costa S, Lauriola V, Vento G, Papacci P, Romagnoli C. Bile acid pneumonia: a "new" form of neonatal respiratory distress syndrome? Pediatrics. 2004;114:269-72.

38. Zecca E, De Luca D, D Barbato G, Marraas M, Romagnoli C. Predicting respiratory distress syndrome in neonates from mothers with intrahepatic cholestasis of pregnancy. Early Hum Dev. 2008;84:337.

39. Nicholas AA. Cholestasis of pregnancy: a review of the evidence. J Perinat Neonatal Nurs. 2005;19: 217-25.

40. Samsioe G, Svendsen P, Johnson P, Gustafson A. Studies In cholestasis of pregnancy Vs. gallbladder disease, liver function tests, serum lipids and fatty acid composition of serum lecithin in the non- pregnant state. Acta Obstet Gynecol Scand. 1975;54:417-23.

41. Glantz A, Marschall HU, Mattsson LA. Intrahepatic cholestasis of pregnancy: relationships between bile acid levels and fetal complication rates. Hepatology. 2004;40:467-74.

42. Lee RH, Incerpi MH, Miller DA, Pathak B, Goodwin TM. Sudden fetal death in intrahepatic cholestasis of pregnancy. Obstet Gynecol. 2009;113:528-31.
43. Qi HB, Shao Y, Wu WX, Zhang JH. Grading of intrahepatic cholestasis of pregnancy. Zhonghua $\mathrm{Fu}$ Chan $\mathrm{Ke} \mathrm{Za} Z \mathrm{Zhi}$ 2004;39:14-7.

44. Huang WM, Gowda M, Donnelly JG. Bile acid ratio in diagnosis of intrahepatic cholestasis of pregnancy. Am J Perinatol. 2009;26:291-4.

45. Ye L, Liu S, Wang M, Shao Y, Ding M. High-performance liquid chromatography-tandem mass spectrometry for the analysis of bile acid profiles in serum of women with intrahepatic cholestasis of pregnancy. J Chromatogr B Analyt Technol Biomed Life Sci. 2007;860:10-7.

46. Tribe RM, Dann AT, Kenyon AP, Seed P, Shennan AH, Mallet A. Longitudinal profiles of 15 serum bile acid in patients with Intrahepatic cholestasis of pregnancy. Am J Gastroenterol. 2010;105:585-95.

47. Lucangioli SE, Castano G, Contin MD, Tripodi VP. Lithocholic acid as a biomarker of intrahepatic cholestasis of pregnancy during Ursodeoxycholic acid treatment. Ann Clin Biochem. 2009;46:44-9.

48. S Iwaki T, Ishizaki K, Kinoshita S, Tanaka H, Fukunari A et al. Protective effects of Ursodeoxycholic acid on chenodeoxycholic acid-induced liver injury in hamster. World J Gastroenterol. 2007;13:5003-8.

49. Pascual MJ, Serrano MA, El-Mir MY, Macias RI, Jiménez F, Marin JJ. Relationship between asymptomatic hypercholanaemia of pregnancy and progesterone metabolism. Clin Sci (Lond). 2002;102:587-93.

50. Ropponen A, Sund R, Riikonen S, Ylikorkala O, Aittomaki K. Intrahepatic cholestasis of pregnancy as an indicator of liver and biliary disease: a population-based study. Hepatology. 2006;43:723-8

51. Macias RIR, Pascual MJ, Bravo A, Alcalde MP, Larena MG, St-Pierre MV et al. Effect of maternal cholestasis on bile acid transfer across the placenta-maternal liver tandem. Hepatology. 2000;31:975-83.

52. Ammala P, Kariniemi V. Short-term variability of fetal heart rate in cholestasis of pregnancy. Am J Obstet Gynecol. 1981;141:217-20

53. Al Inizi S, Gupta R, Gale A. Fetal tachyarrhythmia with atrial flutter in obstetric cholestasis. Int J Gynaecol Obstet. 2006;93:53-4.

54. Sant Anna AM, Fouron JC, Alvarez F. Neonatal cholestasis associated with fetal arrhythmia. J Pediat. 2005;146:277-80.

55. Hirvioja ML, Tuimala R, Vuori J. The treatment of intrahepatic cholestasis of pregnancy by dexamethasone. Br J Obstet Gynaecol. 1992;99:109-11.

56. Walker IA, Nelson- Piercy C, Williamson C. Role of bile acid measurement in pregnancy. Ann Clin Biochem. 2002:39:105-13.

57. Kondrackiene J, Beuers U, Kupcinskas L. Efficacy and safety of Ursodeoxycholic acid versus cholestyramine in Intrahepatic cholestasis of pregnancy. Gastroenterology. 2005;129:894-901. 
58. Gorelik J, Shevchuk AI, Diakonov I, de Swiet M, Lab M, Korchev Y, et al. Dexamethasone and ursodeoxycholic acid protect against the arrhythmogenic effect of taurocholate in an in vitro study of rat cardiomyocytes. BJOG. 2003;110:467-74.

59. Takahashi A, Hasegawa M, Sumazaki R, Suzuki M, Toki F, Suehiro $\mathrm{T}$, et al. Gradual improvement of liver function after administration of ursodeoxycholic acid in an infant with a novel ABCB11 gene mutation with phenotypic continuum between BRIC2 and PFIC2. Eur J Gastroenterol Hepatol. 2007;19:942-6.

60. Marciniak B, Kimber-Trojnar Z, Leszczynska-Gorzelak B, Patro-Malysaza J, Trojnar M, Oleszczuk J. Treatment of obstetric cholestasis with polyunsaturated phosphatidylcholine and Ursodeoxycholic acid. Ginekol Pol. 2011;82:26-31

61. Karaman A, Demirbilek S, Sezgin N, Gurbuz N, Gurses I.
Protective effect of polyunsaturated phosphatidylcholine on liver damage induced by biliary obstruction in rats. J Pediatr Surg. 2003;38:1341-7.

62. Jump DB. Dietary polyunsaturated fatty acids and regulation of gene transcription. Curr Opin Lipidol. 2002;13:155-64.

63. Roncaglia N, Arreghini A, Locatelli A, Bellini P, Andreotti C, Ghidini A. Obstetric cholestasis: outcome. Eur J Obstet Gynecol Reprod Biol. 2002;100:167-70.

64. Mays JK. The active management of intrahepatic cholestasis of pregnancy. Curr Opin Obstet Gynecol. 2010; 22: 100-3.

65. Jain R, Suri V, Chopra S, Chawla YK, Kohli KK. Obstetric cholestasis: outcome with active management. J Obstet Gynaecol Res. 2013 May;39(5):953-9. 